\title{
Parameters of the Summing Reduction Gear Hybrid Car
}

\author{
${ }^{1}$ Stanislav R. Ishinbaev, ${ }^{2}$ Radik M. Galiyev, ${ }^{3}$ Venera M. Nigmetzyanova, ${ }^{4}$ Fedor L. Nazarov \\ ${ }^{1-4}$ Kazan Federal University \\ Email: Slavik.ishinbaev@mail.ru
}

\author{
Received: 20 ${ }^{\text {th }}$ August 2019, Accepted: $30^{\text {th }}$ September 2019, Published: $3^{\text {st }}{ }^{\text {October }} 2019$
}

\begin{abstract}
Cars with an internal combustion engine consume a large amount of fuel and emit harmful substances into the environment with exhaust gases. The ecology problem is especially acute in large cities and near federal highways. At the same time, emissions from automobile transport are growing at a faster pace, and its share in emissions of harmful substances from the transport complex is $89 \%$, because the number of cars is increasing annually. One of the effective directions in solving the problem is the use of electric drive in car designs [1,2].

In transport engineering, such companies as FordMotors, GeneralMotors, Chrysler, Reno, Fiat, Pegeot, Volkswagen, TokyoElectricPowerCo, AseaBrownBoveri and others are engaged in the development of electric drives used in cars and their electrical equipment. $[3,4,5]$.

An example is the development of Volkswagen. This car consists of a diesel engine, a small electric motor and a sodium sulfur battery. When driving at low speeds, the drive wheels are driven by an electric motor, then the internal combustion engine is launched, which provides wheel drive at steady speeds. In this case, the electric motor goes into generator mode. The prototype allowed consuming 4 liters of fuel per 100 kilometers and reducing the toxicity of exhaust gases by $60 \%$ compared with a serial internal combustion engine.

A hybrid car has two energy sources: an internal combustion engine and an electric motor. Each of the engines complements the disadvantages of the other. In this case, the energies of two engines are combined. The matching element or summing reducer can be various types of reducers: chain, belt, gear, planetary, etc. When summing the energy of two engines, it is necessary to coordinate the rotational speeds of the shafts of the internal combustion engine and the electric motor, which are interconnected via a summing reducer.
\end{abstract}

\section{Keywords}

Electric Drive, Hybrid Car, Combined Power Plant, Electromechanical Transmission, Electromechanical Drive, Summing Reducer.

\section{Introduction}

Increasing requirements for fuel efficiency and environmental safety of the car oblige designers to look for innovative solutions to this problem [6].

One of the effective directions in solving these problems is the use of electric drive in car designs. In recent years, two areas of development of cars with electromechanical drives have been clearly identified: the first is the creation of a clean electric vehicle, the second is the development of an electromechanical drive with a combined (hybrid) power plant. Due to the lack of efficient electric energy storage devices available for mass production, pure electric vehicles have relatively low mileage on a single charge. This is one of the main reasons for studying the feasibility and efficiency of using combined power plants in vehicle designs, consisting of two engines (internal combustion engine and electric motor) and an energy storage device. Moreover, any engine can be used as an internal combustion engine: gasoline, diesel, gas [7].

The use of two different energy sources in a passenger car creates three new qualities that cannot be obtained using only an internal combustion engine. One of these qualities is the ability to obtain maximum torque due to the electric motor during dynamic acceleration of the car. The second quality is the energy storage of the main source of the internal combustion engine, if the power it develops is greater than that power implemented on the drive wheels, as well as braking energy using a generator (an electric machine can operate both in electric motor mode and in generator mode). Accumulated energy is used in traction mode, if necessary. The third quality arises from the partial restoration of the energy reserve of the battery due to an external source, which allows reducing the energy received from the internal combustion engine, therefore, reducing fuel consumption and emission of toxic substances into the atmosphere.

The maximum engine power of some passenger cars of newer models currently exceeds $100 \mathrm{~kW}$. Whereas, on average, the power consumption is only $7.5 \mathrm{~kW}$ when driving a car in a populated and non-populated area. In this case, with such small loads on the engine, its efficiency ratio is small and is approximately $20 \%$. A car of $\boldsymbol{B}, \boldsymbol{C}$ class spends on moving not more than $15 \mathrm{~kW}$ on average from beginning to end of the route. Therefore, it is this kind of power that an internal combustion engine shall develop.

When braking, 15 to $60 \%$ of the kinetic energy transmitted by the engine to the vehicle is lost. The share of this loss depends on the type of car and type of movement (in populated, out of populated areas) [8]. With the accumulation of this energy and further use for acceleration or for other purposes, it will reduce the fuel consumption of a car by $20-30 \%$ [9]. Usage of an electric machine (generator mode) will make it possible to recover energy during braking. 


\section{Methods}

When designing a hybrid car, a constructive parallel circuit is more preferable, which, along with improving environmental safety indicators, can increase fuel efficiency [10]. The most common structural diagram of such a car with a wheel formula $4 \times 2$ with a parallel layout is shown in Figure 1 . To coordinate the shaft speeds, the internal combustion engine and the electric machine are interconnected via a summing reducer. In this case, the electric machine can operate in two modes.

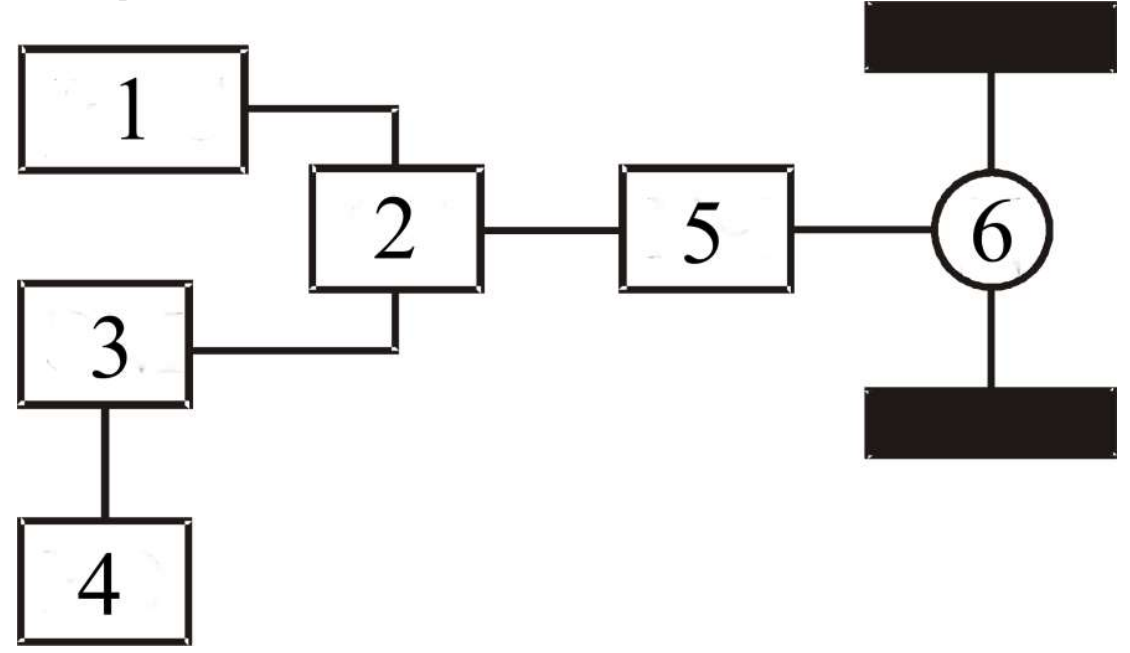

Figure 1: Block Diagram of a Hybrid Car with Parallel Connection Internal Combustion Engine and Electric Machine

( 1- Internal Combustion Engine; 2- Summing Reduction Gear ; 3 - Electric Machine; 4 - Energy Storage; 5 - Transforming Part; 6 Differential.)

Various types of reducers can be used as a summing reducer; for example, chain, gear, belt, planetary, etc. Torques from engines through a planetary summing reducer can be transmitted in total or separately by choice or depending on driving modes and conditions in accordance with the developed structural-kinematic diagram of the car (Figure 2).

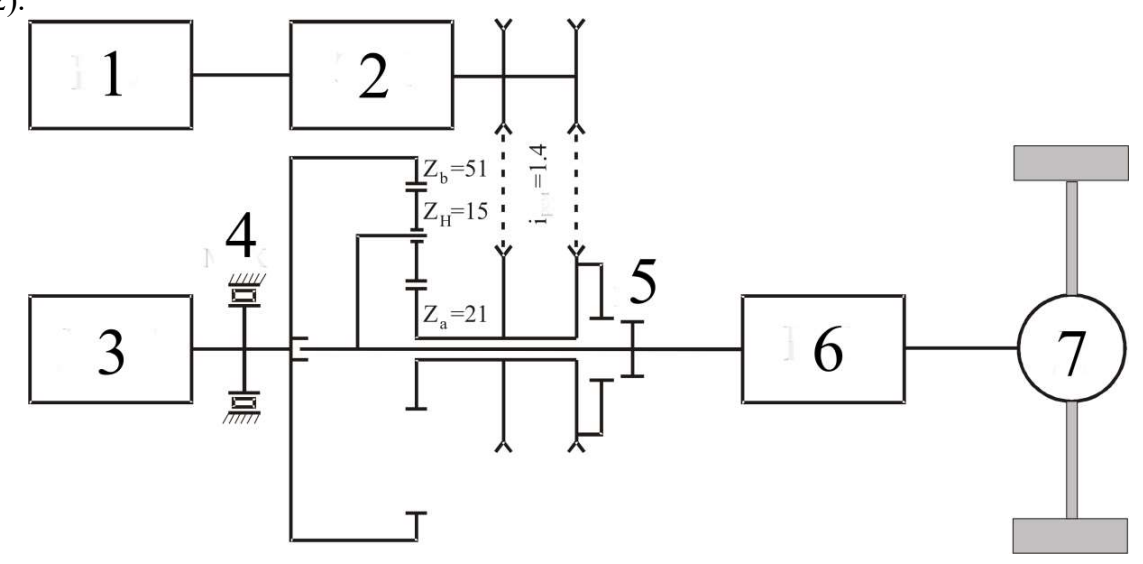

Figure 2: Constructional-Kinematic Scheme of a Hybrid Car with Planetary Summing Reduction Gear (1 - Energy Storage; 2 - Electric Machine; 3 - Internal Combustion Engine; 4 - Free-Running Mechanism to avoid possible counterrotation crankshaft of the internal combustion engine from the torque of the electric motor; 5 - Coupling Lock-up for the implementation of energy recovery in the process of deceleration and braking, and also when you are recharging the energy storage on established car moving speed; 6 - The Transforming Part, including the additional reduction gear, the prop and main gear; 7 - Differential; i $=1.4$ - the gear ratio of the belt drive.)

When calculating the effective forces in gears of planetary gears, centrifugal forces are not taken into account. It is also assumed that the forces between satellites are distributed evenly. Then the design scheme can be presented in accordance with Figure 3. The main wheel interacts with the satellite $\mathbf{g}$ at point $\mathbf{A}$, and the satellite with the crown gear - at point $\mathbf{B}$. Taking into account that the engagement angles are equal, i.e. $\alpha_{\mathrm{w}_{1}}=\alpha_{\mathrm{W}_{2}}$, we find from the equilibrium equation (equality of projections on the horizontal axis) that the force on the carrier is as follows: $\mathrm{F}_{\mathrm{Hg}}=2 * \mathrm{~F}_{\mathrm{ag}} * \mathrm{~K}_{\mathrm{H}} * \cos \alpha_{\mathrm{W}_{1}}=2 * \frac{M_{a}}{r_{a}} * \mathrm{~K}_{\mathrm{H}} * \cos \alpha_{\mathrm{W}_{1}}$, where $\mathrm{K}_{\mathrm{H}}$ - load unevenness coefficient, $\mathrm{r}_{\mathrm{a}}-$ radius of the main circle of the main wheel. The torque transmitted to the transmission units of the car is: 


$$
\mathrm{M}_{\mathrm{H}}=\mathrm{F}_{\mathrm{Hg}} *\left(\mathrm{r}_{\mathrm{a}}+\mathrm{r}_{\mathrm{g}}\right)=-2 * \frac{M_{a}}{r_{a}} * \mathrm{~K}_{\mathrm{H}} * \cos \alpha_{\mathrm{W}_{1}} *\left(\mathrm{r}_{\mathrm{a}}+\mathrm{r}_{\mathrm{g}}\right)=-2 * \mathrm{M}_{\mathrm{a}} * \mathrm{~K}_{\mathrm{H}} * \cos \alpha_{\mathrm{W}_{1}} *\left(1+\frac{z_{H}}{z_{a}}\right)
$$

where $r_{g}$ - radius of the main circumference of the satellite crown gear.

The we have as follows for the engagement angles equal to $20^{\circ}$, and unevenness coefficient $\mathrm{K}_{\mathrm{H}}=1.2$ :

$\mathrm{M}_{\mathrm{H}}=2 * \mathrm{M}_{\mathrm{a}} * 1.2 * \cos 20^{\circ} *\left(1+\frac{15}{21}\right)=-3.86616^{*} \mathrm{M}_{\mathrm{a}}=1.59193 * \mathrm{M}_{\mathrm{b}}$, as $\mathrm{M}_{\mathrm{a}}=\frac{\mathrm{M}_{b}}{p}=-0.41176^{*} \mathrm{M}_{\mathrm{b}}$, where $\mathrm{p}-$ gear ratio of the main wheel to the crown wheel with stationary carrier $\left(\mathrm{p}=-i_{\mathrm{ab}}^{H}\right)$.

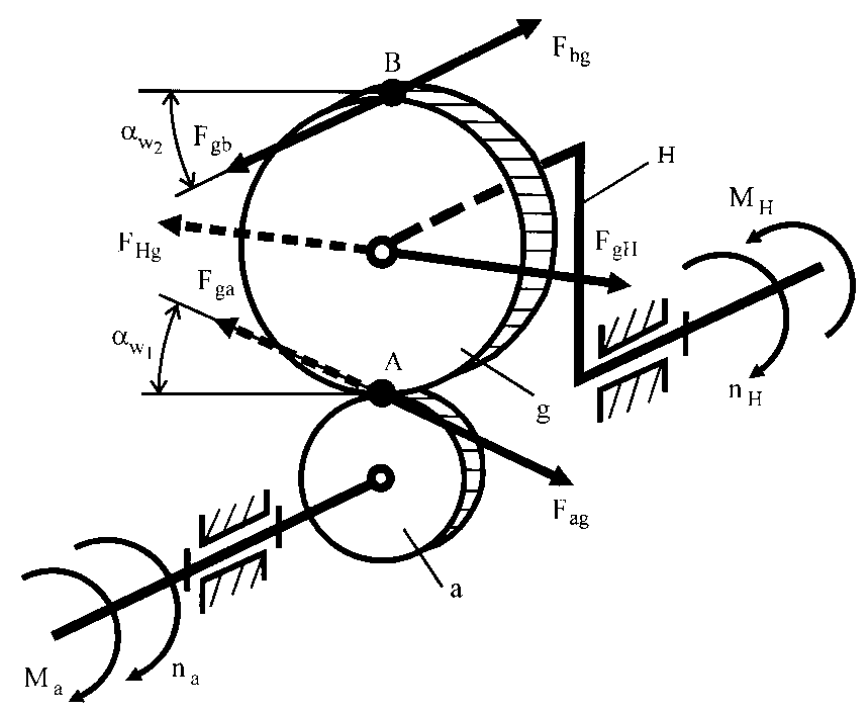

Figure 3: Scheme of Calculating Active Forces in the Planetary Gear

Let us consider the extreme case when the torque of an electric machine (EM) exceeds the permissible one, leading to a stop of the internal combustion engine (ICE) and the possible rotation of its crankshaft in the opposite direction. This condition corresponds to the inequality $\mathrm{F}_{\mathrm{a}}>2 * \mathrm{~F}_{\mathrm{b}}$, i.e. the force $\mathrm{F}_{\mathrm{a}}$ at the contact point of the satellite with the crown wheel (point $\mathbf{B}$ in Figure 3) from the torque of the main wheel $M_{a}$ will have double force $F_{b}$, developed by the torque of the internal combustion engine. At the same time, it is assumed that the force $\mathrm{F}_{\mathrm{a}}$ is transmitted in equal shares to the branch of the internal combustion engine (crown wheel) and to the car transmission (carrier).

Based on the values $F_{a}=\frac{M_{a}}{r_{a}}, F_{b}=\frac{M_{b}}{r_{a}+2 r_{g}}$, the inequality will take the following form: $\frac{M_{a}}{r_{a}}>2^{*}$ $\frac{M_{b}}{r_{a}+2 r_{g}}$. Or after a series of conversions: $M_{a}>0,82353 * M_{b}$. Given the equalities $M_{a}=1.4 * M_{E M}, M_{b}=$

$M_{\text {ICE }}$, we can conclude that when the torque is jointly transmitted through a planetary summing reducer from an electric machine (EM) and an internal combustion engine (ICE) in accordance with the selected design scheme (Figure 2), it is necessary to ensure that the following conditions are met: $M_{\mathrm{EM}}<0.58824 * M_{\mathrm{ICE}}$. Let us write the limit in general form: $M_{a}<\frac{2 M_{b}}{1+2 \frac{Z_{H}}{Z_{a}}}$.

The algorithm for controlling the operation of the electric machine and internal combustion engine is embedded in the electronic control unit.

\section{Results and Discussion}

The development efficiency consists in a significant increase in fuel economy and reduction of toxic emissions with exhaust gases of an internal combustion engine.

Further improvement of the design of the hybrid power plant shall be carried out in the direction of abandonment of the manual transmission used in the transmission and switching to the circuit without the transmission through the use of a planetary summing reducer. Compared with the previously developed hybrid cars, this modernization will provide an additional improvement in the environmental performance of the car, which will lead to a reduction in fuel consumption by estimated data of $7-9 \%$ due to the operation of the internal combustion engine in more economical modes. At the same time, driving will be facilitated due to the fact that there is no need to manipulate the gear lever and clutch pedal during movement and this will affect traffic safety. 


\section{Summary}

The results of the works performed allowed formulating the following main conclusions:

- a parallel layout diagram of a car with an internal combustion engine and an electric machine, from the point of view of indicators of traction and speed properties and efficiency of the car during its operation, is the most rational; - a schematic division of the car into two interconnected components: the power plant and the mechanical part, when describing the car operation, maks it possible to separately develop the mathematical models of the power plant and transmission, which simplifies and accelerates theoretical and computational studies;

- an experimental sample has demonstrated that the developed optimization techniques have improved the fuel economy of the IL-21261 passenger car with virtually no change in its design by $25-31 \%$ due to the use of two engines - a low-power internal combustion engine and an electric direct current machine.

\section{Conclusions}

Based on operational requirements, such as: minimum fuel consumption, environmental damage, improvement of traction and speed properties of the car and possibility of control automation, it follows that the structural diagram of a car with a parallel connection of an internal combustion engine and an electric machine is the most preferred, when summing their power flows in the summing reducer.

The use of a hybrid car of a differential summing reducer from an internal combustion engine and an electric machine in the design will create a stepless electromechanical transmission.

\section{Acknowledgements}

The work is performed according to the Russian Government Program of Competitive Growth of Kazan Federal University.

\section{References}

[1] Mazets V.K. Analysis of the efficiency of hybrid power plants of passenger cars // Materials of the All-Russian Scientific and Practical Conference "Automotive Industry: Design, Construction, Calculation and Technology of Repair and Production". - Izhevsk: Publishing House of IzhGTU, 2013. - P. 99-105.

[2] Imangulov A.R., Filkin N.M. Mathematical modeling of the dynamics of the transmission of a hybrid car of a parallel layout scheme // Intelligent Systems in Production. - 2013. - No. 1(21). - Izhevsk: IzhGTU named after M.T. Kalashnikov. - P. 73-75.

[3] Yaroslavtsev M.V. Determination of parameters of a hybrid car power train by modeling of the energy consumption process. Russian Electrical Engineering. 2014. vol. 85. no. 12. pp. 724-728.

[4] Zhang P., Yan F., Du C. A comprehensive analysis of energy management strategies for hybrid electric vehicles based on bibliometrics. Renewable and Sustainable Energy Reviews. 2015. vol. 48. pp. 88-104.

[5] Jarzebowicz L., Opalinski A. Frequency and time domain characteristics of digital control of electric vehicle in wheel drives. Archives of Electrical Engineering. 2017. vol. 66. no. 4. pp. 829-842.

[6] Galiev R.M., Nigmetzyanova V.M. Features of car operation with a combined power plant // International Technical and Economic Journal. - No. 5 - Moscow: Spectr LLC, 2018. - P. 17-21.

[7] KulakovA.T., GattarovI., FrolovA.M. Provision of gas engine bus performance with air-fuel mixture. Journal of Environmental Management and Tourism. 2015. vol. 6, Issue 1 (11). pp.91-100.

[8] BarykinA.Yu., TakhavievR.Kh., Samigullin A.D. The research of thermal processes of the automobile chassis. International Journal of Mechanical and Production Engineering Research and Development. 2018. vol. 8. pp. 458-464.

[9] Mazets V.K., Filkin N.M. Justification of the main parameters and characteristics of the combined power plant of the car // Materials of the All-Russian Scientific-Practical Conference "Automotive Industry: Design, Construction, Calculation and Technology of Repair and Production" - Izhevsk: Publishing house INNOVA, 2015. - P. 49-53.

[10] Filkin N.M., Umnyashkin V.A., Muzafarov R.S., Mazets V.K. Passenger car with combined power plant // International Scientific and Technical Journal "Transport on Alternative Fuel". Moscow. - 2012. - No. 5. - P. $67-$ 72. 